\title{
CLINICAL EFFICACY OF TACROLIMUS IN INFANTILE HAEMANGIOMA
}

\author{
Loknath Ghoshal1, Arun Achar ${ }^{2}$
}

${ }^{1}$ Assistant Professor, Department of Dermatology, NRS Medical College, Kolkata, West Bengal.

${ }^{2}$ Associate Professor, Department of Dermatology, NRS Medical College, Kolkata, West Bengal.

ABSTRACT

\section{BACKGROUND}

Infantile haemangiomas (IH) are the most common benign vascular tumours in childhood and occur in up to $10 \%$ of infants. Majority of IHs are apparent by the first month of life, rapidly grow till 5 months of age and then undergo a slow but variable regression for months to years. Some IHs, mostly in relation to anatomical site is associated with risks for the patient. Common treatment modalities include topical and systemic steroids, topical timolol- each with individual set of adverse effects. Immune response has been implicated in the involution of IH. Tacrolimus, an immune response modifier applied topically has been already seen to be effective. The present study was an effort to explore this modality.

\section{MATERIALS AND METHODS}

This prospective interventional study was carried out over 12 months. All children newly presenting with superficial IH were considered for the study. Completion of treatment was defined as either 6 months of treatment or full involution (whichever was earlier).

\section{RESULTS}

Two patients (18.2\%) showed excellent response while 5 patients (45.4\%) had good response. Three patients $(27.3 \%)$ showed moderate response, while 1 patient (9.1\%) had poor response. Given the size of populations considered the figures were not statistically significant, but efficacy of tacrolimus was confirmed.

\section{CONCLUSION}

In the absence of a single best option for the treatment of IH, tacrolimus may be another agent in the treatment of IH. In the relative absence of side effects, this drug may be used safely especially when compliance and followup issues are important.

\section{KEYWORDS}

Infantile Haemangioma, Tacrolimus, Immune Response.

HOW TO CITE THIS ARTICLE: Ghoshal L, Achar A. Clinical efficacy of tacrolimus in infantile haemangioma. J. Evolution Med. Dent. Sci. 2017;6(53):3992-3995, DOI: 10.14260/Jemds/2017/863

\section{BACKGROUND}

There are several varieties of vascular tumours, most of which occur in childhood. Infantile haemangiomas (IH) are the commonest benign vascular tumours in this age group and occur in up to $10 \%$ of children in the first year of life. ${ }^{1} \mathrm{IH}$ have a typical proliferative phase followed by a slow phase of involution. Most IHs are apparent by the first month of life, rapidly grow till 5 months of age and undergo a slow and variable regression for months to years. So, by the age of 7 to 10 years some children have complete involution with normal looking skin, while others have telangiectasia, atrophy or scarring.

\section{The Risks Involved and the need for Treatment}

Some IHs, mostly in relation to anatomical site is associated with risks for the patient. Thus, facial and lumbosacral IH in particular deserve regular followup and treatment.

Financial or Other, Competing Interest: None.

Submission 13-06-2017, Peer Review 25-06-2017,

Acceptance 28-06-2017, Published 03-07-2017.

Corresponding Author:

Dr. Arun Achar,

3K, Block-4, 1 Jubilee Park,

Kolkata-700033.

E-mail: achararun@rediffmail.com

DOI: $10.14260 /$ jemds $/ 2017 / 863$
Infants with periocular IHs are in danger for developing anisometropia and amblyopia-both of which may lead to permanent blindness if left untreated. Astigmatism, ptosis, proptosis or strabismus may also develop in addition. IH on the lumbosacral area can have spinal, bony and genitourinary abnormalities in association.

IHs involving the preauricular, mandibular (Beard area) may cause respiratory obstruction.

In general, IHs have excellent prognosis with spontaneous and total involution. However, lesions may lead to significant disfigurement and impairment of vital functions. It has been estimated that up to $20 \%$ of IH need urgent interference due to reasons as bleeding, ulceration and though rarely, fatality. ${ }^{2}$ Thus, decision for treatment may be taken early. ${ }^{3-4}$

Common treatment modalities include observation, corticosteroids (Systemic, ${ }^{5}$ intralesional ${ }^{6}$ and topical), timolol, interferon- $\alpha$, intravenous vincristine, laser therapy and surgery- of which topical corticosteroids and $\beta$ blocker have been studied the most.

Administration of topical ultrapotent corticosteroids may result in atrophy, hypopigmentation and systemic absorption and are most effective for superficial, small, and uncomplicated $\mathrm{IHs}^{7}$

Timolol, a $\beta$ blocker when used topically has been reported to restrain the growth and help regression of superficial IHs. ${ }^{8-9}$ However, there has been apprehension regarding its use as it is $4-10$ times as potent as 
propranolol; ${ }^{10}$ sleep disturbances ${ }^{11}$ and pruritus ${ }^{12}$ have been reported.

There has been suggestion regarding the role of immune response in the regression of IHs. ${ }^{13}$ Imiquimod, an immune response modifier has been found to be effective. ${ }^{14}$ However, this option, too, is questioned by side effects as scaling, crusting and unsightly scars. ${ }^{8}$

During the involution phase, CD8-positive cytotoxic $\mathrm{T}$ cells are recruited and there is suggestion that inhibition of such $\mathrm{T}$ cells could retard regression of haemangiomas. ${ }^{15}$ Thus, calcineurin inhibitors as tacrolimus which inhibit T-cell activation may have a potential effect on the involution of haemangiomas. This option was tried by Lazaridou et al ${ }^{16}$ in 2010. The present study was an effort to explore into this modality.

\section{MATERIALS AND METHODS}

This prospective, experimental, non-randomised, uncontrolled (NRCT) study was carried out in a tertiary care hospital setup in eastern India over 12 months (May 2013 to April 2014). All children presenting with superficial IH with no previous history of treatment for the condition were considered for the study. Necessary informed consent was taken from the parents concerned. Consenting parents were advised tacrolimus $0.03 \%$ ointment to be applied locally twice daily for the first month, then every 2 weeks every month ( 2 weeks on, 2 weeks off). Exclusion criteria were presence of visceral involvement and refusal to be included in the study. Followup visits were scheduled monthly. Completion of treatment was defined as either 6 months of treatment or full involution (Whichever was earlier).

Response was assessed regarding size, colour, consistency and appearance of the lesion at each visit using visual analogue scale. Improvements were noted as 0 $25 \%=1,26-50 \%=2,51-75 \%=3$, more than $76=4$ and recorded in an Excel ${ }^{\circledR}$ sheet (Microsoft Office for windows, v2007). A score of 1 was deemed poor response, 2- partial, 3good response and 4- excellent response. Successful treatment was considered with more than $75 \%$ improvement with no re-growth till one month of stoppage of therapy.

\section{RESULTS}

In all, 17 patients were enrolled for study. Out of them, 11 patients (Table 1) completed the study (attended the last followup).

\begin{tabular}{|c|c|c|c|}
\hline Age of Patients & Sex & $\begin{array}{c}\text { Age of } \\
\text { Gestation }\end{array}$ & $\begin{array}{c}\text { Single/ } \\
\text { Multiple } \\
\text { Pregnancy }\end{array}$ \\
\hline (<1 year) 8 & 4 (Male) & (Term) 6 & (Twin) 3 \\
\hline (> or=1 year) 3 & 7 (Female) & (Preterm) 5 & (Single) 7 \\
\hline \multicolumn{2}{|r|}{ Table 1. Demographic Data of Patients } \\
\hline
\end{tabular}

The age of our patients ranged from 2 months to 14 months. Age of most of the patients were less than 1 year. Most patients were female (7:4, female: male, $n=11)$. Interestingly, 5 of the patients recruited were preterm deliveries, all being female having suffered from complications as foetal distress or premature rupture of membrane. They were all delivered by Caesarean section.
Three patients were born of twin pregnancies. The IH in all the cases were discovered at 1 week to 1 month of age. Six of the IHs were situated on the face, 1 on the neck, 2 on the chest and 2 below the waist (Table 2). The largest IH was situated on the cheek $\left(10.5 \mathrm{~cm}^{2}\right)$.

\begin{tabular}{|c|c|}
\hline Site & Number of Patients \\
\hline Face & 6 \\
\hline Neck & 1 \\
\hline Chest & 2 \\
\hline Below waist & 2 \\
\hline Table 2. Site Wise Distribution of Lesions \\
\hline
\end{tabular}

Two patients (18.2\%) showed excellent response while 5 patients (45.4\%) had good response. Three patients $(27.3 \%)$ showed moderate response, while 1 patient $(9.1 \%)$ had poor response (Table 3).

\begin{tabular}{|c|c|}
\hline Result & Number of Patients \\
\hline Excellent & $2(18.2 \%)$ \\
\hline Good & $5(45.4 \%)$ \\
\hline Moderate & $3(27.3 \%)$ \\
\hline Poor & $1(9.1 \%)$ \\
\hline \multicolumn{2}{|c|}{ Table 3. Response to Treatment } \\
\hline
\end{tabular}

The infants with excellent response were both 2 months of age, one male and female each of single full term pregnancy. They had single haemangiomas, $1.5 \mathrm{X} 1.0 \mathrm{~cm}$ and $4.0 \times 3.0 \mathrm{~cm}$ on the upper lip and perianal region respectively. At the end of treatment, the lesions had lost thickness, area, were pale and except for little scarring, resembled normal skin. Both had not shown any new growth or relapse of the diseases up to 1 month of followup. Side effects of therapy were not complained of.

Amongst the 5 patients showing good response, the youngest patient was of 3 months of age, while the eldest was of 14 months. Three patients were female while 2 were male. Two females were born before term, being delivered by caesarean section due to foetal distress and premature rupture of membranes, respectively. Three were twin pregnancies. One of the $\mathrm{IH}$ was regressing: the others were either growing or were relatively stable at presentation. Most (4 out of 5) were situated on the face, one was on the chest. The largest IH was situated on the cheek $\left(10.5 \mathrm{~cm}^{2}\right)$.

There were 3 patients who showed moderate response. The age of the patients ranged from 8 to 12 months. Two were female, while one was male. Both the female infants were born preterm by Caesarean section due to foetal distress. All of them had stable IH, on the upper eyelid, neck and chest respectively in order of increasing sizes.

The infants with poor response were 2 months of age, female, born preterm due to premature rupture of membrane. The IH had appeared at 1 month of age; the site of involvement was left thigh. At the end of 6 months, lesion had almost no reduction in thickness or in colour. 

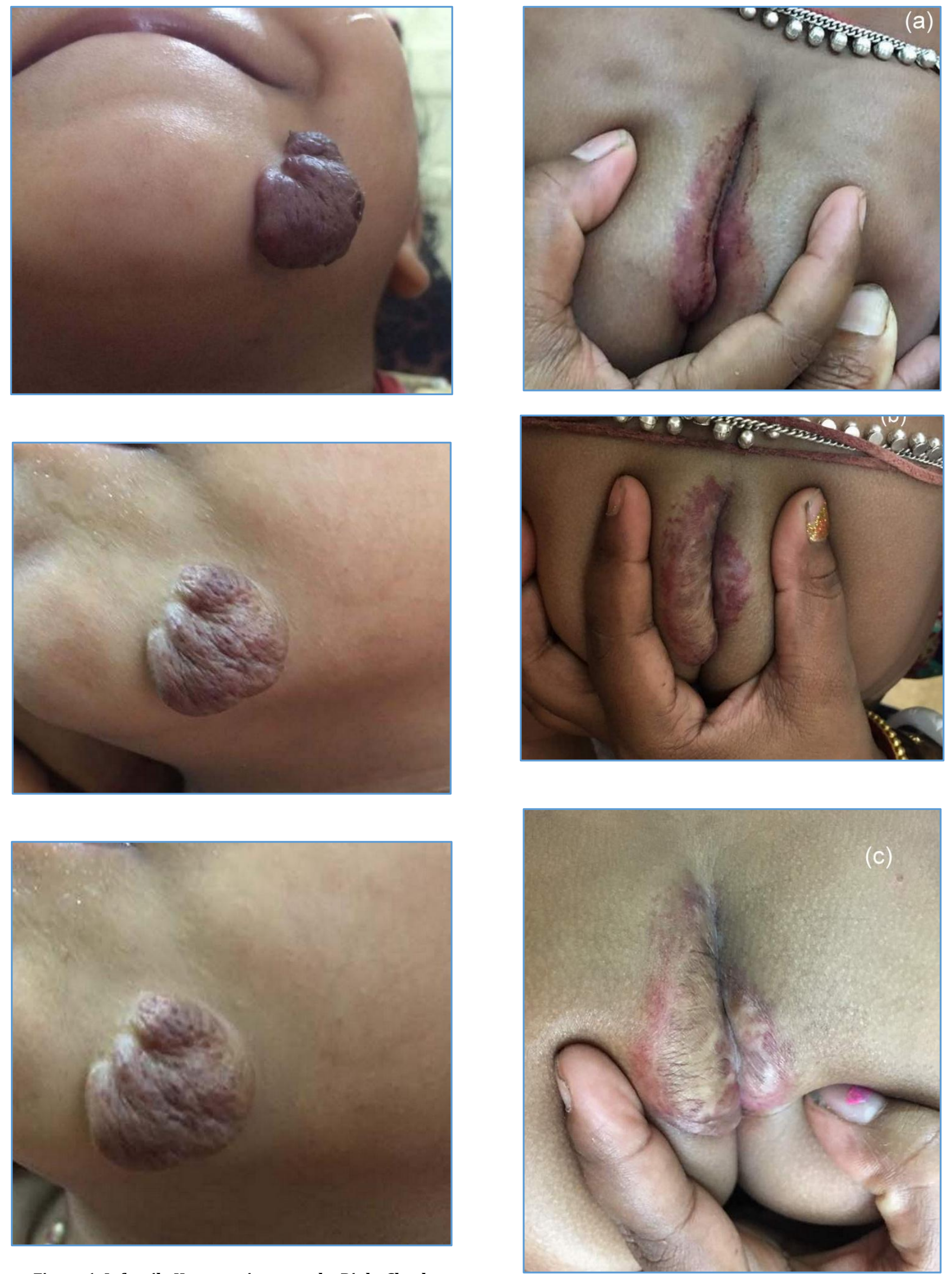

Figure 1. Infantile Haemangioma on the Right Cheek Showing Good Response with Diminution in Colour, Size and Vascularity

Figure 2. Infantile Haemangioma on Perianal Region showing Excellent Response with Progressive Reduction of Vascularity 


\section{DISCUSSION}

Tacrolimus is an immunosuppressant macrolide used widely in Dermatology for the treatment of atopic dermatitis and vitiligo. Lazaridou $\mathrm{E}$ et al studied the topical use of this drug in the treatment of IH for the first time.

In their study, Lazaridou $\mathrm{E}$ et al recruited 6 patients of age between 6 months to 4 years and treated them with tacrolimus or pimecrolimus. The response obtained was good in 2 patients, partial in 3 and none in 1 patient.

Our study involved use of tacrolimus topically as a $0.03 \%$ ointment as an attempt to hasten involution. We obtained excellent response in two patients (18.2\%), good response in 5 patients $(45.4 \%)$, moderate response in 3 patients $(27.3 \%)$, while poor response in 1 patient $(9.1 \%)$.

Given the size of populations considered in both studies, the figures were not statistically comparable, but role of tacrolimus in management of IH was confirmed.

The patients who obtained excellent response were of lower age group ( 2 months, both). Those with good response were of a little higher age $(3,4,5,9$ and 14 months).

Since majority of the IHs were located on the upper parts of the body, no inference regarding correlation of response with the location of the IH could be drawn.

There was no correlation of response with sex of the patient, but apparently, growing IH had better response (bias however remains as majority of patients with lower age group responded favourably; IHs in the lower age group were mostly in the growing phase).

There was no suggestion of any side effect attributable to tacrolimus use.

\section{CONCLUSION}

Presently, there is no single option which might be considered universally effective for all types of IHs. Tacrolimus may be another agent in the treatment of IH. In the relative absence of side effects, this drug may be used safely especially when compliance and followup issues are important.

Further studies in the form of double blinded randomised trials are needed in this direction.

\section{REFERENCES}

[1] Frieden IJ, Haggstrom AN, Drolet BA, et al. Infantile hemangiomas: current knowledge, future directions. Proceedings of a research workshop on infantile hemangiomas, April 7-9, 2005, Bethesda, Maryland, USA. Pediatr Dermatol 2005;22(5):383-406.

[2] Hasan Q, Tan ST, Gush J, et al. Steroid therapy of a proliferating hemangioma: histochemical and molecular changes. Pediatrics 2000;105(1 Pt 1):11720.
[3] Leaute-Labreze C, Prey S, Ezzedine K. Infantile haemangioma. Part II. Risks, complications and treatment. J Eur Acad Dermatol Venereol 2011;25(11):1254-60.

[4] Painter SL, Hildebrand GD. Review of topical beta blockers as treatment for infantile hemangiomas. Surv Ophthalmol 2016;61(1):51-8.

[5] Sagi L, Zvulunov A, Lapidoth M, et al. Efficacy and safety of propranolol for the treatment of infantile hemangioma: a presentation of ninety-nine cases. Dermatology 2014;228(2):136-44.

[6] Couto JA, Greene AK. Management of problematic infantile hemangioma using intralesional triamcinolone: efficacy and safety in 100 infants. J Plast Reconstr Aesthet Surg 2014;67(11):1469-74.

[7] Garzon MC, Lucky AW, Hawrot A, et al. Ultrapotent topical corticosteroid treatment of hemangiomas of infancy. J Am AcadDermatol 2005;52(2):281-6.

[8] Qiu Y, Ma G, Yang J, et al. Imiquimod 5\% cream versus timolol $0.5 \%$ ophthalmic solution for treating superficial proliferating infantile haemangiomas: a retrospective study. Clin Exp Dermatol 2013;38(8):845-50.

[9] Kunzi-Rapp K. Topical propranolol therapy for infantile hemangiomas. Pediatr Dermatol 2012;29(2): 154-9.

[10] McMahon P, Oza V, Frieden IJ. Topical timolol for infantile hemangiomas: putting a note of caution in 'cautiously optimistic'. Pediatr Dermatol 2012;29(1): 127-30.

[11] Chakkittakandiyil A, Phillips R, Frieden IJ, et al. Timolol maleate $0.5 \%$ or $0.1 \%$ gel-forming solution for infantile hemangiomas: a retrospective, multicenter, cohort study. Pediatr Dermatol 2012;29(1):28-31.

[12] Khunger N, Pahwa M. Dramatic response to topical timolol lotion of a large hemifacial infantile haemangioma associated with PHACE syndrome. Br J Dermatol 2011;164(4):886-8.

[13] Sun ZJ, Zhao YF, Zhang WF. Immune response: a possible role in the pathophysiology of hemangioma. Med Hypotheses 2007;68(2):353-5.

[14] Hazen PG, Carney JF, Engstrom CW, et al. Proliferating hemangioma of infancy: successful treatment with topical 5\% imiquimod cream. Pediatr Dermatol 2005;22(3):254-6.

[15] Jia J, Zhao YF, Zhao JH. Potential roles of allograft inflammatory factor-1 in the pathogenesis of hemangiomas. Med Hypotheses 2007;68(2):288-90.

[16] Lazaridou E, Giannopoulou C, Apalla Z, et al. Calcineurin inhibitors in the treatment of cutaneous infantile haemangiomas. J Eur Acad Dermatol Venereol 2010;24(5):611-24. 